\title{
Analysis on Howard Goldblatt's Translation of Mo Yan's Novels from the Perspective of Eco-translatology
}

\author{
Guotai Luo \\ School of Foreign Languages, Nanchang Institute of Technology, Nanchang Jiangxi 330099
}

Keywords: Eco-translatology; Mo Yan’s novels; Howard Goldblatt.

\begin{abstract}
The eco-translatology initiated by domestic scholar Hu Gengshen provides a broader new way of thinking for the translation of Chinese contemporary literature from an ecological perspective. With "translator-centered" concept, the translation process is defined as the translation process of the translator's multi-dimensional adaptation and selection of the translation ecological environment including the author, the original work, the target language reader, and the publisher. This study takes ecological translation as the theoretical framework, and uses Mo Yan's novels and its English translation (translated by American sinologist Howard Goldblatt) as the research corpus. It aims to reveal some characteristics of his translation through case studies, which is the current Chinese literature. The paper demonstrates Howard Goldblatt's selective adaptation to the translational ecological environment of the novel; then uses the methods of description analysis and case study to analyze the adaptive choice of Howard Goldblatt's translation of the ecological environment from the three dimensions of language dimension, culture dimension and communication dimension; Finally, combined with the evaluation standard of translation in ecological translation studies, the integration and adaptation degree of the English translation of the three-dimensional translation degree of the translation is analyzed.
\end{abstract}

\section{Introduction}

In recent years, many scholars have studied the translation of Mo Yan's works from the perspective of sociology and skopos theory, but few have done a thorough inquiry into their translation process. In contrast, the eco-translatology theory advocated by Hu Gengshen, a domestic scholar, provides a more broad new way of thinking for the study of contemporary Chinese literary translation from the perspective of ecology. With the translator as the center, the translation process is defined as the translator's multi dimension adaptation and choice of the translator's ecological environment, such as the author, the original, the target reader, the publisher and so on.

\section{Theory of Eco-translatology}

Eco-translatology, based on the theory of Darwin's "survival of the fittest”, tries to establish a translator centered translation ecological environment, and puts forward the concept of "adaptation and choice” in English translation of Mo Yan's novels. These positive reactions and adaptations, which reveal the adaptation, selection and transformation of the translator's spirit, and the translator's adaptation to the constraints of the translation of the ecological environment provide a new perspective for the study of the translator's subjectivity in literary translation. The research mainly revolves around two ideas: 1) new exploration and discovery of ecological translation or new understanding of translation will bring new enlightenment to translation criticism and its branches; 2) the practice of literary translator's criticism needs some theoretical guidance. Based on this, this study will explain and expand the new ideas and concepts of "translator centered" and "translation ecological environment" in the theory of ecological translation, and integrate the related content with the trend of the development of translation criticism and the demands of development. It provides theoretical guidance for the study of literary translators.

According to the translation adaptation theory, in the process of three-dimensional "adaptive selection conversion" of language dimension, culture dimension and communication dimension, 
"language dimension pays attention to the textual language expression of translation"; "cultural dimension pays attention to the contextual effect of translation"; and communication is concerned with the interpersonal intentions of translation.” During the translation process, the translator should consider the translation language form, communication intention and cultural connotation on the basis of multi-dimensional adaptation to the translation ecological environment with the original text as the "typical element", but the language form transformation, cultural connotation transmission, and communication intention transmission will also follow. The translation of the "typical elements" in the ecological environment varies from one to the other.

\section{The Characteristics of Eco-translatology}

Under the framework of ecological translation, "the translation process is the translator's adaptation to the ecological translation environment with the original text as the typical element and the translation of the translation with the translator as the typical element”. It includes the original author's screening of the target translator (the choice of the translator), the translator's adaptation to the original language and the target language environment, the translator's choice and manipulation of the translation strategy, and the choice of translation content, the adaptation to the target reader's ideology, cognitive model, aesthetic taste and reading habits (translation of the audience, adaptation of the publisher's requirements and rules (the choice of translation channels), the mainstream of the target market The media promotes the adaptation of unspoken rules (the adaptation of translation effects, etc.).

Translator's subjectivity is the subjectivity of translation. It goes through the whole process of translation from beginning to end, including the preparation stage before translation, the choice and adaptation of translators, translation content and strategy, and the evaluation effect after translation. Before the translation, the translator's translation literacy, the choice of translation content, the evaluation of the target audience, and the understanding of the target sales market largely determine the pros and cons of the translation. In the translation, the translator plays a dynamic "dual" role: the translator must accept the choice and restriction of the ecological environment that is, the choice of the translation subject and the translation content. At the same time, the translator is also the subject of the ecological translation environment. After the translation, the communication and coordination between the translator and the original author, the publishing house, and the client, that is, the communication channel of the translation media determines the survival and survival of the translation.

\section{The Influence of Howard Goldblatt on Mo Yan's Novels}

American sinologist Howard Goldblatt is known as "Western Chief Chinese literary translator" who has a strong international reputation. Under the framework of ecological translation studies, the translator can only win the inferior and win the favor of the original author if he has excellent translation talents and actively adapts to the original author's writing style and translation requirements. Howard Goldblatt himself has unique charm - excellent translator's potential, the translator's requirements of Mo Yan, adapted to the ecological translation environment of the main body of the translation of Mo Yan's novels. Howard Goldblatt has a profound bilingual knowledge, is both proficient in English and in Chinese culture. The literary savvy and artistic sentiment, the translation skills are even more powerful. As done by Gladys, "Let Chinese literature be immersed in the colors of contemporary British and American literature" (Bao Xiaoying, 2014: 63). At the same time, as a senior expert in the international translation community, the high popularity of Howard Goldblatt has accumulated rich social capital and symbolic capital. Howard Goldblatt, a critic, sinologist, scholar, translator, and judge of the international major awards, strongly recommended the promotion of Mo Yan's works in the West. The literary world has won countless readers.

In order to adapt to the needs of the mainstream poetics and ideology of the translated language, Howard Goldblatt carefully selected the subject matter of the work and carefully thought about it. 
Because the final translation wants to win the favor of the target audience, it must be filtered and screened by Western mainstream ideology. For Mo Yan, Howard Goldblatt is a unique judge of talent, and Howard Goldblatt's choice of Mo Yan is a wise move. Adhering to a heartfelt love for Chinese literature, Howard Goldblatt, who is deeply fascinated by Chinese culture, explores the great potential of Mo Yan's literary works with his sharp and unique insights - and is universal and regional. Mo Yan's works are rich in local flavor, distinctive in regional characteristics, delicate in language, lively and simple, witty and humorous, and colorful. The multi-dimensional and unique narrative perspective integrates the elements of drama with fear factors, beauty and ugliness, and finally adopts magical realism. Western readers have built a strange and mysterious legend of Shandong Province.

\section{The Analysis on Howard Goldblatt's Translation of Mo Yan's Novels}

The adaptive selection transformation of the language dimension refers to the translator's adaptive selection transformation of the language form in the translation process. The translator's adaptation to the language form is carried out in different aspects and at different levels. The famous translation theorist A. Nida said in his book Language, Culture and Translation: "The role of language in culture and the influence of culture on words and idioms are so common. If you are not familiar with the language and culture background, no one is. I can understand the meaning very well." Even though Howard Goldblatt has many years of Chinese experience, excellent Chinese talent and profound Chinese heritage, in order to be as faithful as possible to the original text, he is also very rigorous, often written for a word or novel. He did not know the East and Mo Yan repeatedly negotiated. At the same time, he also believes that mastering the mother tongue is the decisive factor in the success of translation. On the issue of translating Chinese literary works, Howard Goldblatt is faithful to the original text and the translation. It can be seen that the selection of translation strategies is closely related to the cultural position of the translator's wooden body. Therefore, the translation methods of naturalization, alienation and rewriting are used in Howard Goldblatt's translation works. In translation, he used the "alternative "approach in dealing with the relationship between form and meaning, and the choice of the image and content of the novel. In the translation of Gao Yang, wife and apricot flower in the Song of People's Taiwanese Garlic, Howard Goldblat's adaptation in the language dimension is very authentic, translated the proverb of "wife" into her mother, the verb "say " was converted into "answered", also increased an adverb tersely makes people feel that her mother (the wife of Gao Yang) is unhappy because of the unlucky words of apricot flower saying "end" at the time of harvest, so the language blames the apricot flower. The translator uses the word "reach down" to describe the movement of apricot flower. It is very visual and very expressive. Different from the original sentence in the original sentence, Howard Goldblatt in the English translation, the subject of this dialogue is saved with "we", enhance the logical relationship of the sentence, and more importantly reflects After being imprisoned, Gao Yang recalled the sorrow and bitterness of the family when it was poor but it was a happy life. By properly adding, Howard Goldblatt not only retains the original title and image, but also tries to achieve the bilingual shape and meanings.

Howard Goldblatt believes that "translation is an intercultural communication activity". "How translators translate source works into target language culture and how to deal with complex cross-cultural communication activities are all issues to be considered." The soul of Mo Yan's novels, when he was translating, paid great attention to the grasp of the cultural, social and historical background of the novel, and the degree of multicultural thinking was also high. He commented that Mo Yan's The Republic of Wine is the most imaginative and complex in its creative approach. In the novel, the word "Laozi” appeared 29 times, the main three different meanings: (1). It is the name of oneself, referring to the meaning of "father", he translated into "your sire" which is generally translated into colloquialism to convey the attitude of the original text; (2). It is to the speaker himself. The name is often used in quarrels with people. It is a strong tone. It is directly translated by personal pronouns according to the situation; (3). It is a weakened name, which mainly conveys a kind of pressure. The method of naturalization accurately makes adaptive 
selection and transformation, and clearly expresses the meaning of the original text. Howard Goldblatt tries to conform to the original intention and the context in translation, in order to maximize the reading effect of the target reader. In order to stimulate readers' curiosity and interest in foreign cultures, Howard Goldblatt tries to convey the equivalent of rhetoric, culture and other information, and tries to retain the original image. Language is the carrier of culture. Howard Goldblatt accurately grasps the cultural pulse of the source language in the translation. The specific situation is treated concretely. As the "mediator" of the cultural question, the adaptive selection transformation of the cultural dimension is successfully realized, which is the source language and the translated language. There is a bridge between cultural information transmission.

The adaptive selection transformation of the communication dimension means that the translator pays attention to the adaptive selection transformation of the bilingual communication intention in the translation process; the adaptive selection transformation of the communication dimension is based on the transformation of the language dimension and the cultural dimension, and pushes the focus to the communication. On the level, pay attention to the embodiment of the communicative intention in the original text in the translation.

In the process of translation, the translator is first of all the "reader" of the original text, followed by the "author" of the translation. Translators with dual identities are different from ordinary readers and authors, but with people with clear translation intent and implementation of translation tasks. Howard Goldblatt's translation of Mo Yan's novels is to hope that the readers of the Chinese side can understand the history and culture of China and realize the purpose of intercultural communication through the transformation of language and culture. "The nature of translation is rewriting," Howard Goldblatt translated Mo Yan's novels with a large number of "rewrite" translation methods, there are reasons for the original itself, the consideration of the acceptance of the target readers, as well as the reasons for publishing economics. This rewriting, one is the adjustment of the structure of the novel. For example, "The Song of People's Church Garlic", "That is a story full of anger, and there is no such thing as the end." So he proposed a revised opinion, and Mo Yan also accepted it, even when the original reprint was based. The translation was revised. The second is the addition and deletion of content and space. When translating "Red Sorghum Family", "Song of the Church of the People", "The Country of Wine", he added "the translation of this article...there is no such thing as the original in the original book, such as sexual description", but in the translation of "Life and Death" , a more sexual description was removed. Howard Goldblatt's translation of Mo Yan's novels, this large-scale "rewriting”, is to meet the reading expectations and reading habits of the target audience. Mo Yan once said that as a senior translator, Howard Goldblatt has extensive experience in dealing with his works. What he thinks most when he translates is not the writer but the reader. He considers the habits of western readers and cuts down the background content of political history, which is of positive significance.

\section{Conclusion}

From the perspective of ecological translation, Howard Goldblatt's English translation of Mo Yan's novels is not only to explore the adaptability of ecological translation theory to the specific translation practice guidance, but also to examine the effective interpretation of ecological translation studies by Howard Goldblatt's translation practice of Mo Yan's novels. Howard Goldblatt's choice and adaptation of the text reflects the harmonious unification of the translational ecological environment, and the three-dimensional transformation of the translation process realizes the balance of translation ecology. In the competition of translation ecology, Howard Goldblatt's translation has been maintained "the fittest for the long turn" through the "survival of the fittest". Eco-translating shifts the previous discussion of translation strategies and methodologies to the translation environment, so the various ecological elements that influence the translation process need to be considered. For the American sinologist Howard Goldblatt to translate the Chinese writer Mo Yan's novels, the translator and the original works, the original authors, and the readers and publishers of the translated-language world from the source language world are the harmonious unity of adaptation and choice. 


\section{Acknowledgement}

Project funding: Jiangxi Province Humanities and Social Science Project (NO.: YY 1431)

\section{References}

[1] Hu Gengshen. Research focus and theoretical perspective of ecological translation studies [J]. Chinese Translation, 2011 (2): 5-9.

[2] Shen Dan. Research on Howard Goldblatt's Translation from the Perspective of Ecological Translation Studies [J]. Journal of Wuyi University (Social Sciences Edition), 2013, (03):55-140.

[3] Jiang Yuhua. Study on the Characteristics of Howard Goldblatt's English Translation of "Red Sorghum Family” [J].Foreign Languages and Translation; 2015(02).

[4] Sun Huijun. Research on Howard Goldblatt's Translating Mo Yan's Novels [J].Chinese Translation, 2014(05)

[5] Bao Xiaoying. Research on the Translation Model of "Going Abroad" in Chinese Literature_-Taking the American Translation of Mo Yan's Works as an Example[D]. Shanghai: Shanghai International Studies University, 2014.

[6] Song Zhiping, Hu Gengshen. Ecological Interpretation of Some Key Issues in Translation Studies [J].Foreign Language Teaching, 2016(01) 